\title{
Article \\ In-Band Pumped Thulium-Doped Tellurite Glass Microsphere Laser
}

\author{
Elena A. Anashkina 1,*(D), Vitaly V. Dorofeev ${ }^{1,2}$ and Alexey V. Andrianov ${ }^{1}$ \\ 1 Institute of Applied Physics of the Russian Academy of Sciences, 46 Ul'yanov Street, \\ 603950 Nizhny Novgorod, Russia; dorofeev@ihps-nnov.ru (V.V.D.); andrian@ipfran.ru (A.V.A.) \\ 2 G.G. Devyatykh Institute of Chemistry of High-Purity Substances of the Russian Academy of Sciences, \\ 49 Tropinin Street, 603950 Nizhny Novgorod, Russia \\ * Correspondence: elena.anashkina@ipfran.ru
}

Citation: Anashkina, E.A.; Dorofeev, V.V.; Andrianov, A.V. In-Band Pumped Thulium-Doped Tellurite Glass Microsphere Laser. Appl. Sci. 2021, 11, 5440. https://doi.org/ 10.3390/app11125440

Academic Editor: Stefano Pelli

Received: 19 April 2021

Accepted: 8 June 2021

Published: 11 June 2021

Publisher's Note: MDPI stays neutral with regard to jurisdictional claims in published maps and institutional affiliations.

Copyright: (c) 2021 by the authors. Licensee MDPI, Basel, Switzerland. This article is an open access article distributed under the terms and conditions of the Creative Commons Attribution (CC BY) license (https:// creativecommons.org/licenses/by/ $4.0 /)$.

\begin{abstract}
Microresonator-based lasers in the two-micron range are interesting for extensive applications. $\mathrm{Tm}^{3+}$ ions provide high gain; therefore, they are promising for laser generation in the two-micron range in various matrices. We developed a simple theoretical model to describe Tmdoped glass microlasers generating in the 1.9-2 $\mu \mathrm{m}$ range with in-band pump at $1.55 \mu \mathrm{m}$. Using this model, we calculated threshold pump powers, laser generation wavelengths and slope efficiencies for different parameters of Tm-doped tellurite glass microspheres such as diameters, Q-factors, and thulium ion concentration. In addition, we produced a 320- $\mu \mathrm{m}$ tellurite glass microsphere doped with thulium ions with a concentration of $5 \cdot 10^{19} \mathrm{~cm}^{-3}$. We attained lasing at $1.9 \mu \mathrm{m}$ experimentally in the produced sample with a Q-factor of $10^{6}$ pumped by a C-band narrow line laser.
\end{abstract}

Keywords: microlaser; microsphere; Tm-doped tellurite glass; in-band pump; numerical simulation

\section{Introduction}

Whispering gallery mode (WGM) resonators with high Q-factors and a small mode volume providing efficient light-matter interaction are very attractive photonic elements for obtaining optical frequency combs for different applications [1-9], creating optical filters, switches, microlasers, sensors, and other miniature optoelectronic devices [10-16]. Microlasers in the two-micron range are potentially interesting for extensive application in remote chemical sensing, biomedicine, and atmosphere monitoring. Lasing in the two-micron range is easily achieved in microspheres doped with $\mathrm{Tm}^{3+}$ and/or $\mathrm{Ho}^{3+}$ ions (sometimes with the addition of other co-dopants) [17-26]. Due to high gain of $\mathrm{Tm}^{3+}$ ions, lasing is easily achieved in various glass matrices such as silica [17], tellurite [18-20], fluorotellurite [21], fluoride [22], and even chalcogenide [23].

Tellurite glasses are of great interest for the development of microlasers in the twomicron range [18]. Current technologies allow producing low-loss tellurite glasses characterized by substantial solubility of rare-earth ions [27], which is beneficial in fabricating such photonic devices. Additionally, a high linear refractive index $n \sim 2$ for tellurite glasses leads to an emission cross section higher than for silica glass with refractive index $n \sim 1.4$ [27], since the cross section is proportional to $\left(n^{2}+2\right)^{2} / 9 n$.

Despite a large number of experimental studies on laser generation in thulium-doped microresonators made of different glasses, insufficient attention has been paid to theoretical models and numerical investigations. There are only a few theoretical studies of Tm-doped microlasers. A rather complex theoretical model for lasing at $\sim 2 \mu \mathrm{m}$ in a Tm-doped tellurite microsphere coupled with an undoped microsphere was proposed and studied in the recent work by M. Saffari et al. [28]. Recently, we investigated theoretically the possibility of single-color and multi-color cascade lasing at wavelengths of about 1.9, 1.5, and $2.3 \mu \mathrm{m}$ in Tm-doped tellurite microspheres pumped at $792 \mathrm{~nm}$ [29]. Diagrams of various regimes were plotted depending on the parameters of the system (such as Q-factors and pump 
powers) [29]. After that, P. Wang et al. demonstrated experimentally dual-wavelength lasing at 1.9 and $2.3 \mu \mathrm{m}$ for the first time in a Tm-doped fluorotellurite microsphere [21], thus confirming the performance of our theoretical model [29]. Here, we concentrate on studying laser generation in the 1.9-2 $\mu \mathrm{m}$ range at the ${ }^{3} \mathrm{~F}_{4} \rightarrow{ }^{3} \mathrm{H}_{6}$ transition of $\mathrm{Tm}^{3+}$ ions with in-band pump in the range of about $1.55 \mu \mathrm{m}$, which is highly attractive for many practical applications. Currently, there are plenty of commercially available laser sources at $1.55 \mu \mathrm{m}$ demanded in telecom applications; therefore, their use for pumping thulium microlasers is a fairly straightforward solution. The simple theoretical model presented here can be used to describe Tm-doped microlasers based on various glass matrices, including tellurite (which is also analyzed in detail in this work), silica, fluorotellurite, fluoride, and others.

Microlasers based on different active rare-earth ions can be described by a system of ordinary differential equations of the first order in time [30,31]. The most common way to analyze such microlasers is numerical solution of a dynamical system (commonly by the Runge-Kutta method). A steady state solution that is of the greatest interest can be found by simulating the laser dynamics over a long time sufficient for relaxation oscillations to decay [31]. However, with a large number of WGMs falling into the gain band of an active ion, the dynamical system contains a very large number of coupled equations, which can take a lot of time to solve, especially for many realizations with varied parameters. When considering continuous wave (CW) generation under $\mathrm{CW}$ pump, a solution can be found by solving a system of many nonlinear algebraic equations (of the order of the number of modes) obtained by taking $\mathrm{d} / \mathrm{d} t=0$. However, we have proposed another semi-analytical approach allowing us to solve only a single nonlinear algebraic equation using exhaustive search for each mode (or a combination of modes) and to find stable CW generation regimes [29]. Here, to describe CW lasing in the 1.9-2 $\mu \mathrm{m}$ range in a Tm-doped microsphere, we use the same approach which becomes very simple for in-band pump.

\section{Theoretical Model}

The general scheme of the analyzed system is shown in Figure 1. It consists of a thulium-doped tellurite glass microsphere and a silica fiber taper for both, coupling the CW pump wave and extracting the generated laser wave.

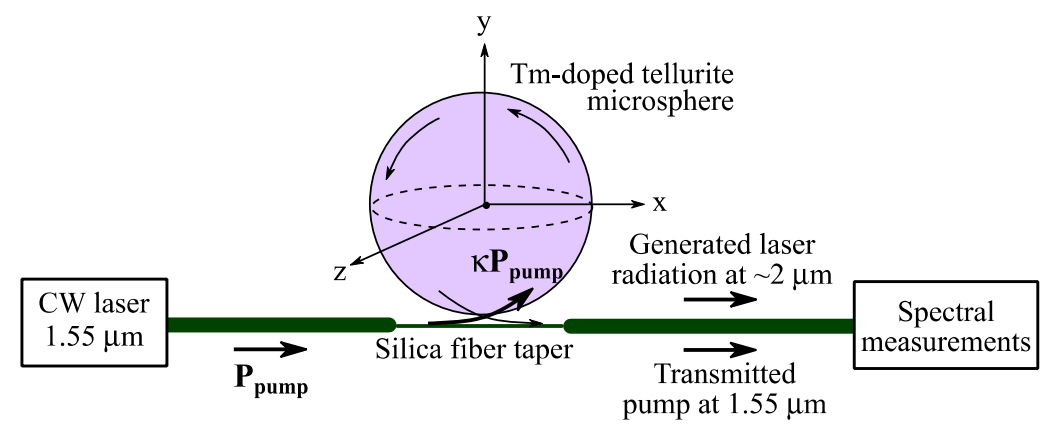

Figure 1. A simplified scheme of the considered system. $\mathrm{P}_{\text {pump }}$ is a pump power and $\mathrm{k}$ is a coupling coefficient.

We consider in-band CW pump $\left({ }^{3} \mathrm{H}_{6} \rightarrow{ }^{3} \mathrm{~F}_{4}\right)$ at a wavelength of $1.55 \mu \mathrm{m}$ and lasing in the $2 \mu \mathrm{m}$ range $\left({ }^{3} \mathrm{~F}_{4} \rightarrow{ }^{3} \mathrm{H}_{6}\right)$ as shown in Figure 2a. The cross-relaxation process, which can play an important role for a pump at $\sim 0.79 \mu \mathrm{m}$ [32], is neglected here, because levels above ${ }^{3} \mathrm{~F}_{4}$ are almost unpopulated under in-band pump. Here, we used the two-level approximation, which is equivalent to the quasi three-level model because the transition from the pump level to the upper laser level (both belong to the ${ }^{3} \mathrm{~F}_{4}$ manifold) is very rapid at a room temperature, so the population of the pump level is almost zero (please see Appendix A for details). Let us define the population densities of the ${ }^{3} \mathrm{H}_{6}$ and ${ }^{3} \mathrm{~F}_{4}$ 
levels as $n_{1}$ and $n_{2}$. They are normalized to the concentration of $\mathrm{Tm}^{3+}$ ions $N_{T m}$ and satisfy the expression

$$
n_{1}+n_{2}=1 .
$$
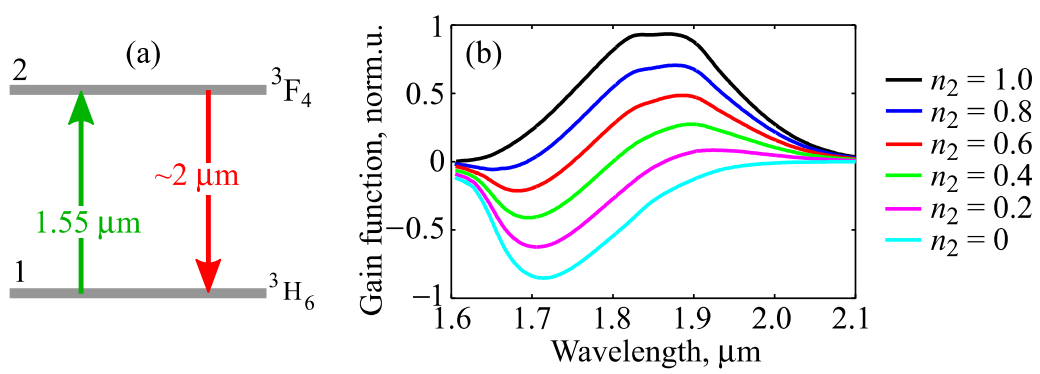

Figure 2. (a) A simplified scheme of laser levels for in-band pump. (b) Normalized gain function proportional to $\left(\sigma_{e m} n_{2}-\sigma_{a b s} n_{1}\right)$.

An important characteristic is a gain function proportional to $\left(\sigma_{e m} n_{2}-\sigma_{a b s} n_{1}\right)$, where $\sigma_{e m}$ and $\sigma_{a b s}$ are the emission and absorption cross sections, respectively. The calculated normalized gain function depending on wavelength is given in Figure $2 \mathrm{~b}$. The wavelength corresponding to the maximum of the function depends on $n_{2}$ and determines the generated wavelength. Note that the emission cross-section at the pump wavelength $\lambda_{p}=1.55 \mu \mathrm{m}$ is almost zero $\sigma_{e m}\left(\lambda_{p}\right) \approx 0$ for similar tellurite glasses [33,34].

The rate equation for the ground state population is $[32,34,35]$ :

$$
\frac{d n_{1}}{d t}=-W_{12} n_{1}+\left(W_{21}+\frac{1}{\tau_{21}}\right) n_{2}
$$

where $\tau_{21}=3 \mathrm{~ms}$ [32] is the lifetime of the ${ }^{3} \mathrm{~F}_{4}$ level and $W_{12,21}$ are the stimulated absorption and emission rates (assuming $\sigma_{e m}\left(\lambda_{p}\right) \approx 0$ )

$$
\begin{gathered}
W_{12}=\frac{\Gamma \lambda_{p} \sigma_{a b s}\left(\lambda_{p}\right)}{h c S_{e f f}}\left|A_{p}\right|^{2}+\frac{\Gamma}{h c S_{e f f}} \sum_{l} \lambda_{s, l} \sigma_{a b s}\left(\lambda_{s, l}\right)\left|A_{s, l}\right|^{2}, \\
W_{21}=\frac{\Gamma}{h c S_{e f f}} \sum_{l} \lambda_{s, l} \sigma_{e m}\left(\lambda_{s, l}\right)\left|A_{s, l}\right|^{2} .
\end{gathered}
$$

Here, $\lambda_{s, l}$ is the laser wavelength with the mode order $l$ (we consider here only the family of fundamental modes with angular mode order $l$ ), $h$ is Planck's constant, $c$ is the speed of light in vacuum, $S_{\text {eff }}$ is the effective mode field area, $\Gamma=0.95$ is the overlap factor (defined in [28]), $A_{p}$ is the intracavity field amplitude at the pump wavelength, and $A_{s, l}$ is the intracavity field amplitude at laser wavelength. For the fundamental mode family, the overlap factor is almost independent on the laser wavelength in the 1.9-2 $\mu \mathrm{m}$ range. We calculated previously that for the fundamental mode family, $S_{\text {eff }}$ is almost a linear function of the tellurite microsphere radius changing from $S_{\text {eff }} \approx 6 \mu \mathrm{m}^{2}$ up to $S_{\text {eff }} \approx 20 \mu \mathrm{m}^{2}$ when the radius increases from $50 \mu \mathrm{m}$ to $200 \mu \mathrm{m}$ [36].

The temporal evolution of the intracavity field amplitudes inside the microsphere can be described by the system of ordinary differential Equations [29-31,35]:

$$
\begin{gathered}
\frac{d A_{p}}{d t}=-\frac{1}{2}\left(\frac{1}{T_{e f f}}-g_{p}-i \Delta \omega\right) A_{p}+i \sqrt{\frac{1}{T_{e x t} T_{R T}}} E_{\text {pump }} \\
\frac{d A_{s, l}}{d t}=-\frac{1}{2}\left(\frac{1}{T_{e f f}}-g_{s, l}\right) A_{s, l}
\end{gathered}
$$




$$
\begin{gathered}
g_{p}=-\frac{c \Gamma N_{T m}}{\sqrt{\varepsilon}} \sigma_{a b s}\left(\lambda_{p}\right) n_{1} \\
g_{s, l}=\frac{c \Gamma N_{T m}}{\sqrt{\varepsilon}}\left(\sigma_{e m}\left(\lambda_{s, l}\right) n_{2}-\sigma_{a b s}\left(\lambda_{s, l}\right) n_{1}\right),
\end{gathered}
$$

where $\Delta \omega$ is detuning of the pump with amplitude $E_{\text {pump }}$ from the nearest WGM (further we take $\Delta \omega=0) ; T_{\text {eff }}$ is the effective lifetime $1 / T_{\text {eff }}=1 / T_{0}+1 / T_{\text {ext }} ; T_{0}$ is the intrinsic lifetime (without allowance for ground state absorption); $T_{\text {ext }}$ is the coupling lifetime; $T_{R T}$ is the round trip time (circulating time inside the microsphere); $\varepsilon$ is the permittivity (the square of the refractive index). We neglect the difference between these lifetimes for different wavelengths and WGMs inside the gain band.

The intracavity laser power is $P_{s, l}=\left|A_{s, l}\right|^{2}$ and the output laser power is

$$
P_{s, l}^{\text {out }}=\left|\sqrt{\frac{T_{R T}}{T_{\text {ext }}}} A_{s, l}\right|^{2}=\kappa P_{s, l}
$$

where the coupling coefficient $\kappa$ is

$$
\kappa=\frac{T_{R T}}{T_{\text {ext }}} .
$$

For a steady-state solution, the time derivatives in Equations (2), (5) and (6) are equal to zeros

$$
\begin{gathered}
\frac{d n_{1}}{d t}=0, \\
\frac{d A_{p}}{d t}=0, \\
\frac{d A_{s, l}}{d t}=0 .
\end{gathered}
$$

Therefore, the system of Equations (2), (5) and (6) with (1), (3), (4), (7) and (8) taken into account becomes algebraic, and the number of equations originating from (6) is determined by the number of the considered WGMs in the gain band. However, the solution of a nonlinear system containing a lot of algebraic equations is not a trivial task. Therefore, we use the following semi-analytical approach. First of all, we assume that lasing is singlemode (which is certainly valid near the threshold). We use an exhaustive search for each $l$ in Equation (6) and after that choose only stable physically meaningful solutions (with $0<n_{1}<1$ and $P_{s, l}>0$ ). Stability of the solutions is analyzed as follows. If a lasing WGM has the order $l^{*}$, then for all other WGMs with orders $l \neq l^{*}$ the zero solution $A_{s, l}=0$ must be stable, that is the increment in Equation (6) must be $<0$ :

$$
-\frac{1}{2}\left(\frac{1}{T_{e f f}}-g_{s, l \neq l *}\right)<0 .
$$

Therefore, for the WGM with number l, Equation (6) with allowance for Equation (8) takes the form

$$
\frac{1}{T_{e f f}}-\frac{c \Gamma N_{T m}}{\sqrt{\varepsilon}}\left(\sigma_{e m}\left(\lambda_{s, l}\right) n_{2}-\sigma_{a b s}\left(\lambda_{s, l}\right) n_{1}\right)=0 .
$$

Using Equation (1), we find $n_{1}$ and $n_{2}$ from Equation (15):

$$
\begin{aligned}
& n_{1}=\frac{\sigma_{e m}\left(\lambda_{s, l}\right)}{\sigma_{e m}\left(\lambda_{s, l}\right)+\sigma_{a b s}\left(\lambda_{s, l}\right)}-\frac{1}{T_{e f f}} \frac{\sqrt{\varepsilon}}{c \Gamma N_{T m}} \frac{1}{\left(\sigma_{e m}\left(\lambda_{s, l}\right)+\sigma_{a b s}\left(\lambda_{s, l}\right)\right)}, \\
& n_{2}=\frac{\sigma_{a b s}\left(\lambda_{s, l}\right)}{\sigma_{e m}\left(\lambda_{s, l}\right)+\sigma_{a b s}\left(\lambda_{s, l}\right)}+\frac{1}{T_{e f f}} \frac{\sqrt{\varepsilon}}{C \Gamma N_{T m}} \frac{1}{\left(\sigma_{e m}\left(\lambda_{s, l}\right)+\sigma_{a b s}\left(\lambda_{s, l}\right)\right)},
\end{aligned}
$$




$$
\left|A_{p}\right|^{2}=\frac{\left(4 / T_{R T}^{2}\right) \cdot \kappa P_{p u m p}}{\left(\frac{1}{T_{e f f}}+\frac{c \Gamma N_{T m}}{\sqrt{\varepsilon}} \sigma_{a b s}\left(\lambda_{p}\right) n_{1}\right)^{2}} .
$$

After that, from Equation (2) with Equation (1) and the expressions (3), (4) taken into account, we determine the intracavity power at the laser wavelength

$$
\left|A_{s, l}\right|^{2}=\frac{\left|A_{p}\right|^{2} \lambda_{p} \sigma_{a b s}\left(\lambda_{p}\right) n_{1}-\frac{n_{2} h c S_{e f f}}{\tau_{21} \Gamma}}{\lambda_{s, l}\left(\sigma_{e m}\left(\lambda_{s, l}\right) n_{2}-\sigma_{a b s}\left(\lambda_{s, l}\right) n_{1}\right)} .
$$

Therefore, we have obtained the analytical expression (19) for $\left|A_{s, l}\right|^{2}$ for each WGM with number $l$ from the gain band, where $n_{1}, n_{2}$, and $\left|A_{p}\right|^{2}$ are given by the expressions (16), (17) and (18), respectively. Further, we execute exhaustive search for all $l$, select only physically meaningful solutions and for them examine the stability using the expression (14). We verified that for any set of parameters, there is only one stable solution resulting in laser generation at a fixed wavelength (or no lasing under the threshold).

\section{Theoretical Results and Discussion}

We consider critical coupling when an intrinsic $\mathrm{Q}$-factor is equal to a coupling $\mathrm{Q}$-factor: $Q_{0}=Q_{\text {ext }}$ (in other words when $T_{\text {eff }}=T_{0} / 2=T_{\text {ext }} / 2$ ). We set $\sigma_{\text {abs }}\left(\lambda_{p}\right)=0.05 \cdot 10^{-20} \mathrm{~cm}^{2}$ and the emission/absorption cross sections at laser wavelengths as in the paper [34]. We varied $\mathrm{Tm}^{3+}$ ion concentrations, microsphere diameters, $\mathrm{Q}$-factors, and pump powers. The calculated coefficients $\kappa$ as functions of the total Q-factor for different diameters of a tellurite microsphere ranging from $40 \mu \mathrm{m}$ to $400 \mu \mathrm{m}$ are plotted in Figure $3 \mathrm{a}$ as well as expected laser wavelengths (Figure $3 b$ ), slope efficiencies (Figure 3c), threshold pump powers (Figure $3 \mathrm{~d}-\mathrm{f}$ ), and threshold values of coupling coefficients multiplied by pump powers (Figure $3 \mathrm{~g}-\mathrm{i}$ ) as functions of the varied parameters of the system. Figure $3 \mathrm{~d}$ demonstrates that for a $\mathrm{Tm}^{3+}$ ion concentration of $1 \cdot 10^{19} \mathrm{~cm}^{-3}$, lasing is possible only if the Q-factor exceeds $10^{6}$. For lower Q-factors, losses are too large and the gain cannot compensate them; the laser threshold is not reached. With an increase in active ion concentrations to $N_{T m}=5 \cdot 10^{19} \mathrm{~cm}^{-3}$ and $N_{T m}=110^{20} \mathrm{~cm}^{-3}$, the gain according to Equation (8) grows, and the minimum Q-factors required for generation become equal to $3 \cdot 10^{5}$ and $2 \cdot 10^{5}$, respectively (Figure $3 \mathrm{e}, \mathrm{f}$ ). Figure $3 \mathrm{~d}-\mathrm{f}$ also demonstrate that for a certain active ion concentration, the larger the microsphere diameter, the higher the threshold pump power is.

Figure $3 \mathrm{~d}-\mathrm{f}$ show that with an increase in the Q-factor, the threshold pump powers first decrease, then reach a minimum, and then begin to increase. This has the following explanation. At low $\mathrm{Q}$-factors, a large intracavity pump power is required to overcome losses and reach the lasing threshold. As the Q-factor increases, less losses need to be compensated, so the threshold power decreases. However, at high Q-factors, the coupling coefficient is rather small (see Figure 3a), because $\kappa$ is inversely proportional to the total $\mathrm{Q}$-factor for the critical coupling. The intracavity pump power becomes lower than for medium Q-factors, which explains the non-monotonic behavior of the curves in Figure $3 \mathrm{~d}-\mathrm{f}$. For a clearer demonstration, we plot the dependence of the threshold values of coupling coefficients multiplied by pump powers on Q-factor (Figure 3g-i). These curves are monotonic: the higher the Q-factor, the lower intracavity power is required to attain lasing.

Let us go back to the expected lasing wavelength. We found that in the used model, it does not depend on the diameter of the microsphere and the pump power, but depends on $\mathrm{Q}$-factor and active ion concentration. At low $\mathrm{Q}$-factors, a higher pump power is required, so the population $n_{2}$ of the level ${ }^{3} \mathrm{~F}_{4}$ is rather high, so the maximum gain is achieved at shorter wavelengths near the maximum of the emission cross section (see Figure $2 \mathrm{~b}$ ). With an improved Q-factor, the laser wavelength grows smoothly. Knowing experimental $\lambda_{s}$ and $N_{T m}$, it is possible to compare the measured value of the Q-factor with the calculated one or even estimate the effective Q-factor (if it is not measured experimentally). 

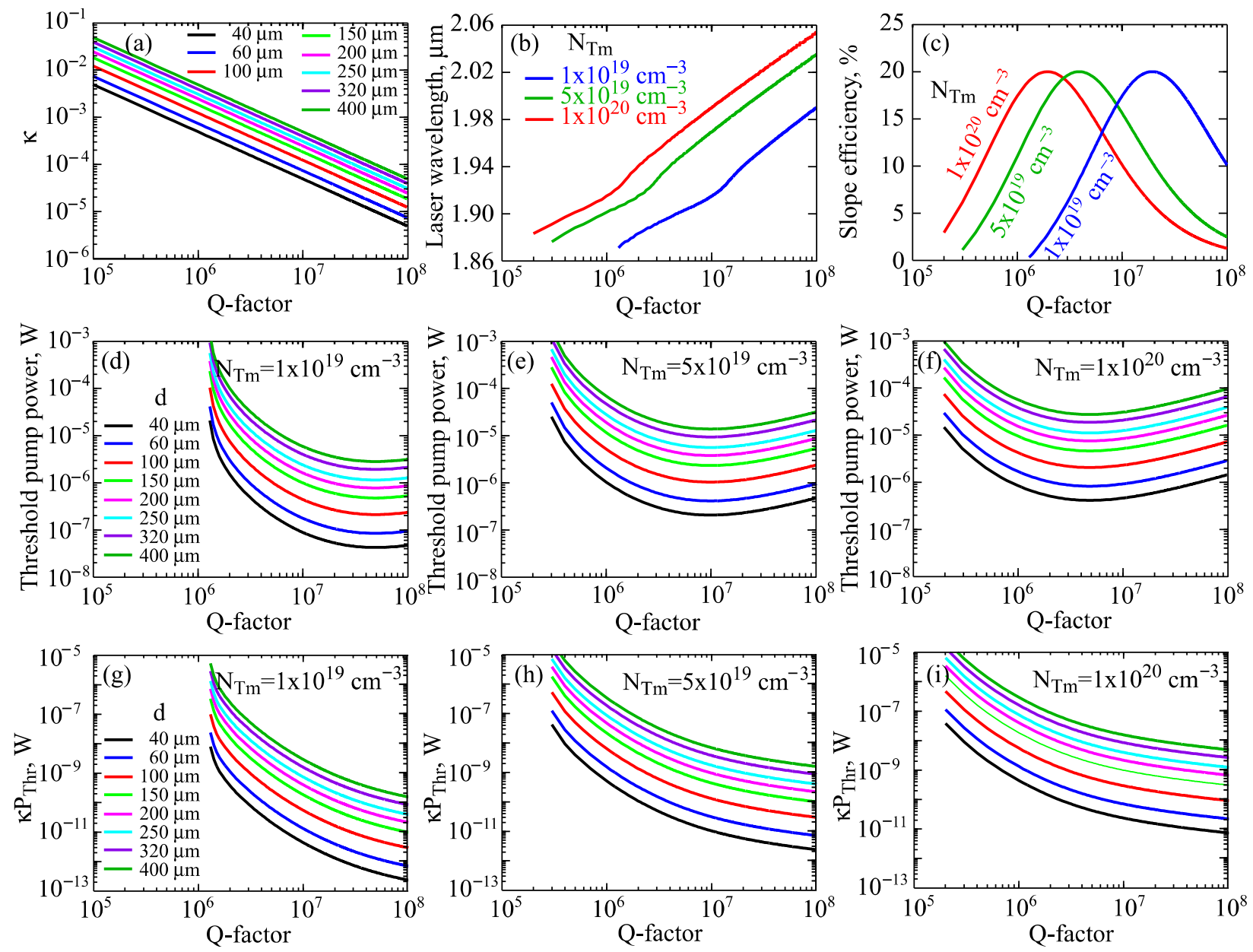

Figure 3. (a) Calculated coupling coefficients $\kappa$ as functions of the total Q-factor for different diameters of tellurite microspheres indicated in the legend. Calculated laser wavelengths (b) and slope efficiencies (c) above the threshold pump power as functions of the total Q-factor for different thulium ion concentrations $N_{T m}$. Threshold pump powers for different microsphere diameters $d$ for thulium ion concentration of $1 \cdot 10^{19} \mathrm{~cm}^{-3}(\mathbf{d}), 5 \cdot 10^{19} \mathrm{~cm}^{-3}(\mathbf{e})$, and $1 \cdot 10^{20} \mathrm{~cm}^{-3}(\mathbf{f})$. Threshold values of $\kappa P_{T h r}$ (pump powers multiplied by coupling coefficients) for different microsphere diameters $d$ for thulium ion concentration of $1 \cdot 10^{19} \mathrm{~cm}^{-3}(\mathrm{~g}), 5 \cdot 10^{19} \mathrm{~cm}^{-3}(\mathbf{h})$, and $1 \cdot 10^{20} \mathrm{~cm}^{-3}(\mathbf{i})$. The legend shown in subplots $(\mathbf{d}, \mathbf{g})$ is the same as for subplots $(\mathbf{d}-\mathbf{i})$.

The slope efficiencies calculated for pump powers above the threshold are plotted in Figure 3c. They do not depend of microsphere diameters. There is an optimal Q-factor to attain maximum efficiency, which coincides with the general laser theory according to which there is an optimal value of transmission coefficient of a laser resonator (or optical losses) to obtain the maximum output laser power [35].

Our semi-analytical model, which allows fast simulation of a steady-state solution unlike dynamical models used previously, makes it possible to perform a scan over a broad range of laser parameters. The obtained results may serve as a guide for designing Tm-doped microlasers pumped by readily available pump sources at a telecommunication wavelength. The model describing single-mode laser generation works well for not very high excess of pump power over the threshold. To describe multi-mode laser generation in different mode families, which is observed for high excess over the threshold, the model can be modified.

\section{Experimental Results and Discussion}

An experimental microsphere was made of $\mathrm{TeO}_{2}-\mathrm{ZnO}-\mathrm{La}_{2} \mathrm{O}_{3}-\mathrm{Na}_{2} \mathrm{O}$ glass doped with thulium ions with concentration $N_{T m}=5 \cdot 10^{19} \mathrm{~cm}^{-3}$. This glass was similar in composition 
and method of preparation to the core of the fiber used for laser generation earlier [34]. The glass was prepared by melting the initial high-purity oxides and sodium carbonate $\mathrm{Na}_{2} \mathrm{CO}_{3}$ in platinum crucible inside sealed a silica chamber in the atmosphere of purified oxygen. After several hours melting at $800^{\circ} \mathrm{C}$, the melt was poured into a mold of silica glass and annealed at a glass transition temperature. A glass sample was cut, ground, and polished (see a photo in Figure 4a). The sample did not contain noticeable point scattering defects and striae in the glass volume. A polished parallelepiped was examined in a red laser beam to determine point defects. He-Ne laser beam scanning did not reveal bubbles and scattering inclusions in the volume of the samples (see Figure $4 \mathrm{~b}$ ). A single-index fiber was produced from the prepared glass (see Figure 4c). Next, we fabricated a microsphere with diameter $d=320 \mu \mathrm{m}$ by softening the tapered end of this tellurite single-index fiber using a resistive micro-heater [36].
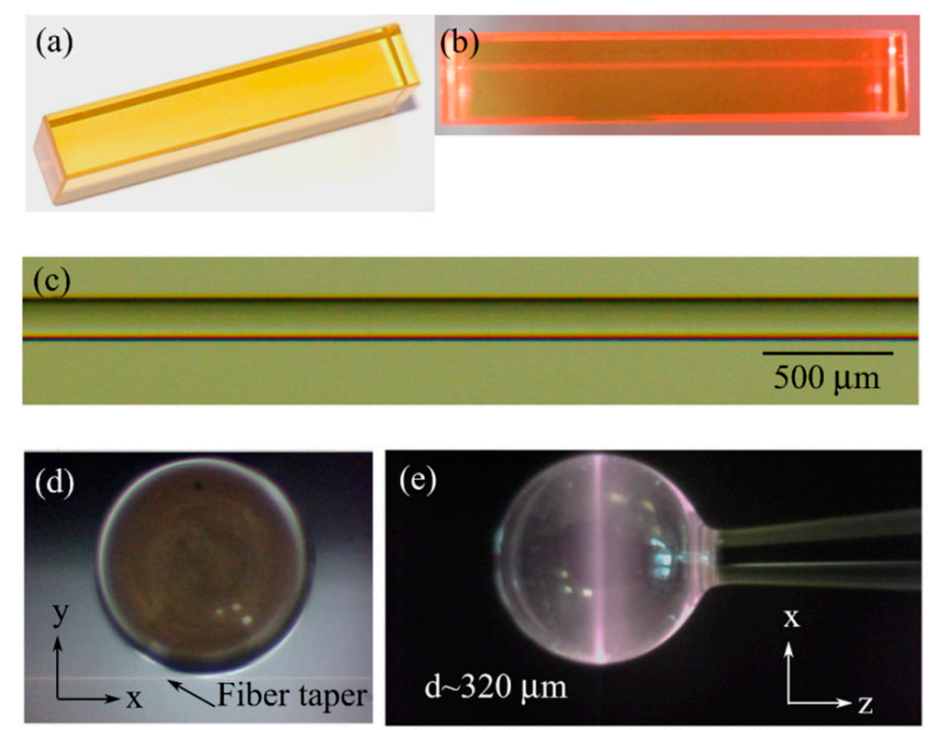

Figure 4. (a) A photography of the polished thulium-doped tellurite glass parallelepiped with dimensions of $8 \times 8 \times 44 \mathrm{~mm}$. (b) A photography of He-Ne laser beam in this sample. (c) A microphotography of single-index fiber produced from the synthesized glass. (d,e) The images of the experimentally produced tellurite glass microsphere in perpendicular planes from two CCD cameras. The coordinate axes in $(\mathbf{d}, \mathbf{e})$ correspond to the axes in Figure 1.

Coupling of the pump wave at $1.55 \mu \mathrm{m}$ to the tellurite microsphere and outcoupling of the generated laser wave at $\sim 1.9 \mu \mathrm{m}$ were realized with a silica fiber taper as schematically shown in Figure 1. Despite the significant refractive index difference between silica and tellurite glasses, it is possible to achieve large (critical and even overcritical) coupling in the experiment. This is evident from the fact that at small distances between the taper and the microsphere the measured fraction of absorbed power near the resonance can be more than 0.5 .

For an in-band pump and Q-factor measurements, we used a standard telecommunication C-band laser based on a micro-integrable tunable laser assembly (Pure Photonics, PPCL550-180-60, line width $10 \mathrm{kHz}$, tuning range 190.3-197.9 THz). The measured Q-factor at a wavelength of $1.52 \mu \mathrm{m}$ was $\sim 10^{6}$. To measure the $\mathrm{Q}$-factor, we chose the wavelength shorter than the pump wavelength to mitigate the impact of ground state absorption of thulium ions on effective Q-factor. Note that our value $Q=10^{6}$ agrees well with the Q-factors of tellurite microspheres reported previously by other researches [20,24].

The experiment was conducted in an acrylic glove box to protect the microsphere and fiber taper against dust and airflows from the conditioning system [37]. The fiber taper was made of a telecommunication fiber SMF28e [38]. Coarse adjustment of relative position of the microsphere and fiber taper was done manually using two CCD cameras recording 
images in perpendicular planes. An example of images from CCD cameras is given in Figure $4 \mathrm{~d}$,e, where one can also see near-IR light ("pink belt" in the equatorial plane) that is explained by very weak (neglected in simulation) energy transfer up-conversion processes in thulium ions (the pump light at $1.55 \mu \mathrm{m}$ is invisible to our CCD cameras). Sub $0.1-\mu \mathrm{m}$ adjustment of the relative position between the microsphere and the silica taper was implemented with a 3-axis translation stage with precision piezo actuators (Thorlabs MAX312D). The output spectrum of the transmitted pump light was recorded by Telecom OSA (Optical Spectrum Analyzer) Yokogawa AQ6370D (600-1700 nm). To record the spectrum of laser generation beyond the spectral boundary of Telecom OSA, we used a scanning grating monochromator (MS2004i, SOL Instruments Ltd., Minsk, Belarus) and an amplified PbSe detector (PDA20H, Thorlabs) integrated into the computer controlled setup.

Figure 5 demonstrates a composite spectrum of the transmitted pump wave (in $\mathrm{dB}$ scale) and the generated laser wave (in linear scale). The pump power launched to the taper is about $5 \mathrm{~mW}$. The laser wavelength is about $1.9 \mu \mathrm{m}$, which agrees with the numerical results shown in Figure $3 \mathrm{~b}$, where for $N_{T m}=5 \cdot 10^{19} \mathrm{~cm}^{-3}$ and Q-factor of the order of $10^{6}$, the expected laser wavelength is the same. We estimated the threshold power absorbed in the resonator as $0.5 \mathrm{~mW}$. The slope efficiency estimated by modulating the pump power and measuring the response of the generated laser signal was about $10 \%$, which also agrees with theoretical predictions (see Figure 3c, where for $N_{T m}=5 \cdot 10^{19} \mathrm{~cm}^{-3}$ and Q factor of $10^{6}$, the calculated value is $11 \%$ ). Note that measurements of dependencies of the laser output characteristics on the pump power are complicated because changes in the pump power result in changes of the heat dissipated in the microresonator and the corresponding shift of WGM resonance [36], thus changing the pump coupling conditions.

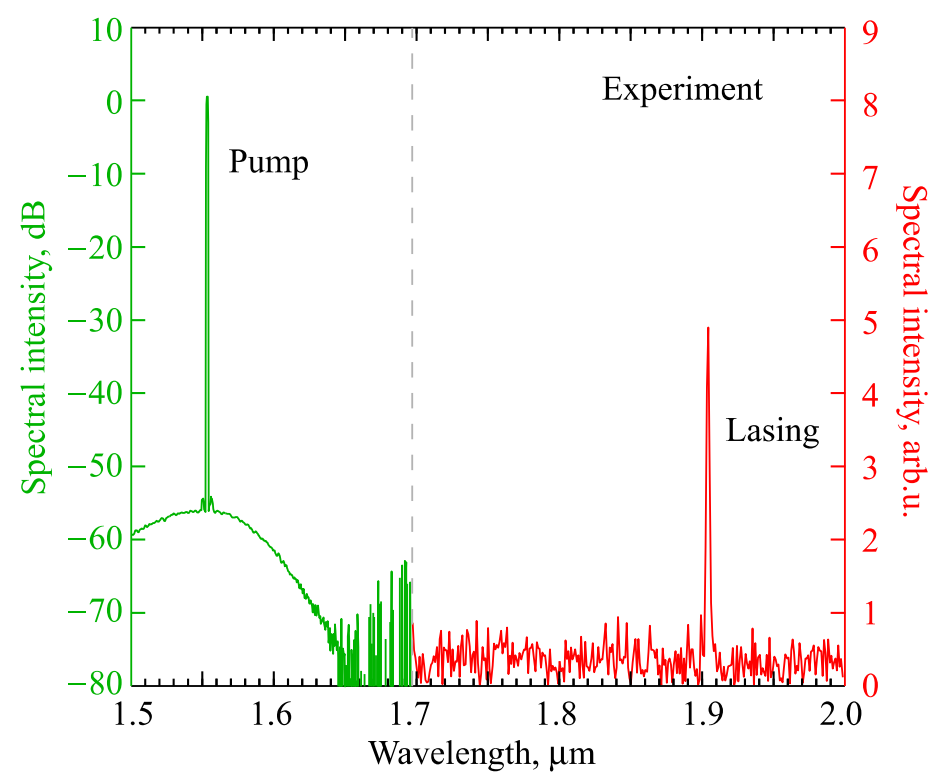

Figure 5. The experimental spectra of the transmitted pump wave (green, left axis, recorded by Telecom OSA in $\mathrm{dB}$ scale) and the generated laser wave (red, right axis, obtained using monochromator and $\mathrm{PbSe}$ detector in a linear scale).

Note, despite the fact that lasing in Tm-doped tellurite microspheres was achieved in several works listed in Table 1, an in-band pump was used only in [20]. In [20], at a $\mathrm{Tm}^{3+}$ concentration of $4.2 \times 10^{20} \mathrm{~cm}^{-3}$ for a microsphere with a $\mathrm{Q}$ factor of $2 \times 10^{6}$, the central lasing wavelength was $1975 \mathrm{mn}$, which agrees with the results of our theoretical prediction. Therefore, we believe that our experimental and theoretical work can be useful in the development of relatively simple Tm-doped in-band pumped microlasers. 
Table 1. Performance of $\mathrm{Tm}^{3+}$-doped tellurite glass microsphere lasers.

\begin{tabular}{ccccc}
\hline Thulium Ion Content & Diameter of Microsphere, $\boldsymbol{\mu m}$ & Pump Source; Wavelength, $\boldsymbol{\mu m}$ & Laser Wavelength, $\boldsymbol{\mu m}$ & Reference \\
\hline $5 \cdot 10^{19} \mathrm{~cm}^{-3}$ & 320 & Telecommunication laser, 1.55 & $\sim 1.9$ & Present study \\
\hline $4.2 \cdot 10^{20} \mathrm{~cm}^{-3}\left(1 \mathrm{~mol}^{2} \mathrm{Tm}_{2} \mathrm{O}_{3}\right)$ & 30 & Tunable laser source, $1.504-1.629$ & Centered at $\sim 1.975$ & {$[20]$} \\
\hline $0.15 \% \mathrm{Tm}_{2} \mathrm{O}_{3}$ & 104 & Ti: sapphire, 0.8 & $\sim 1.5 \& 1.9$ & $\sim 1.5 \& 1.9$ \\
\hline $0.5 \mathrm{wt} \% \mathrm{Tm}_{2} \mathrm{O}_{3}$ & Not reported & Ti: sapphire, 0.793 & $\sim 2.0$ & {$[40]$} \\
\hline $5 \mathrm{wt} \%$ & 25 & Ti: sapphire, 0.793 & $\sim 19]$ \\
\hline $1 \mathrm{~mol} \% \mathrm{Tm}_{2} \mathrm{O}_{3}$ & $\sim 60$ & Laser diode, 0.793 & $\sim 1.92 \& 2.35 ; \sim 1.90$ & {$[21]$} \\
\hline
\end{tabular}

\section{Conclusions}

We have developed a simple theoretical model to describe thulium-doped glass microlasers generating in the 1.9-2 $\mu \mathrm{m}$ range with in-band CW pump at $1.55 \mu \mathrm{m}$. We have obtained an analytical expression for laser power assuming single-mode generation and further performed exhaustive search for each WGM from the gain band and after that chose the wavelength corresponding to a stable physically meaningful solution. This model can be used for microspheres made of different glasses such as silica, tellurite, fluorotellurite, fluoride, chalcogenide, and others. To describe the system, the following parameters are required: emission and absorption cross sections for the ${ }^{3} \mathrm{~F}_{4} \rightarrow{ }^{3} \mathrm{H}_{6}$ energy transition, the lifetime of the ${ }^{3} \mathrm{~F}_{4}$ level, linear refractive index, $\mathrm{Tm}^{3+}$ ion concentration, Q-factor, coupling coefficient, microsphere diameter, and pump power. We have performed a theoretical analysis for tellurite glass microspheres promising for lasing in the two-micron range. It has been shown that laser generation is possible if the Q-factor exceeds a certain value depending on active ion concentration. The expected laser wavelength depends on thulium ion concentration and Q-factor. The higher the concentration and Q-factor, the longer the laser wavelength is. There is an optimal Q-factor to attain the maximum slope efficiency for a certain thulium ion concentration. Additionally, we have fabricated a $320-\mu \mathrm{m}$ tellurite glass microsphere doped with thulium ions with a concentration of $5 \cdot 10^{19} \mathrm{~cm}^{-3}$. We have attained laser generation at $1.9 \mu \mathrm{m}$ experimentally in the produced sample with a Q-factor of $10^{6}$ pumped by a C-band CW narrow line laser at $1.55 \mu \mathrm{m}$. The observed laser wavelength and slope efficiency agree with the theoretical calculation for the same Q-factor.

Author Contributions: Conceptualization, E.A.A. and A.V.A.; methodology, E.A.A., V.V.D. and A.V.A.; software, E.A.A. and A.V.A.; validation, E.A.A. and A.V.A.; investigation, E.A.A. and A.V.A.; resources, A.V.A. and V.V.D.; data curation, E.A.A.; writing-original draft preparation, E.A.A.; writing-review and editing, A.V.A.; visualization, E.A.A.; project administration, E.A.A.; funding acquisition, E.A.A. All authors have read and agreed to the published version of the manuscript.

Funding: The work was funded by the Russian Science Foundation, Grant No. 20-72-10188.

Institutional Review Board Statement: Not applicable.

Informed Consent Statement: Not applicable.

Data Availability Statement: Not applicable.

Conflicts of Interest: The authors declare no conflict of interest.

\section{Appendix A}

Here, we show the equivalence of the two-level and quasi three-level models for our system. Let us define in the three-level model: the ground state ${ }^{3} \mathrm{H}_{6}$ as " 1 ", the upper laser level as " 2 " and the pump level as " 3 ". Note that level 2 and level 3 belong to the same ${ }^{3} \mathrm{~F}_{4}$ manifold. For glass matrices, intra-band transitions $3 \rightarrow 2$ are very rapid at a room temperature $\left(\tau_{32} \rightarrow 0\right)$, so the population of level 3 is close to zero $\left(n_{3} \rightarrow 0\right)$. Therefore, the 
expression for three-level model $n_{1}+n_{2}+n_{3}=1$ reduces to $n_{1}+n_{2}=1$, which coincides with Equation (1).

Two-level model

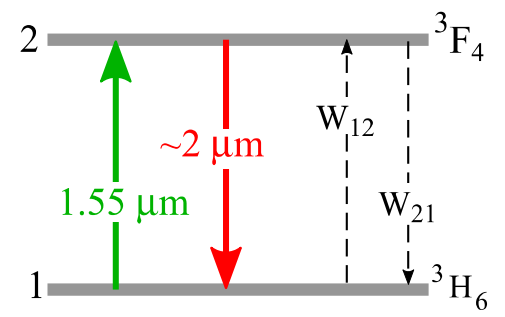

Three-level model

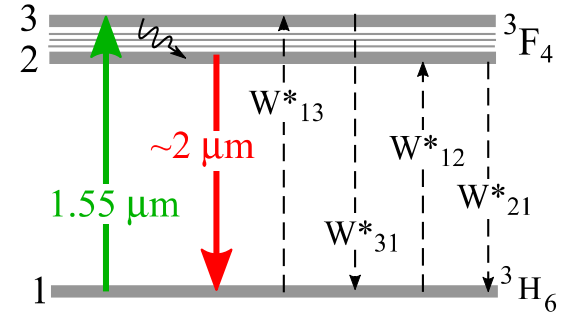

Figure A1. Simplified scheme of laser levels for the two-level and three-level models.

Further, the stimulated absorption and emission rates for the three-level model (see Figure A1) are

$$
\begin{gathered}
W *_{12}=\frac{\Gamma}{h c S_{e f f}} \sum_{l} \lambda_{s, l} \sigma_{a b s}\left(\lambda_{s, l}\right)\left|A_{s, l}\right|^{2} \\
W *_{21}=\frac{\Gamma}{h c S_{e f f}} \sum_{l} \lambda_{s, l} \sigma_{e m}\left(\lambda_{s, l}\right)\left|A_{s, l}\right|^{2}, \\
W *_{13}=\frac{\Gamma \lambda_{p} \sigma_{a b s}\left(\lambda_{p}\right)}{h c S_{e f f}}\left|A_{p}\right|^{2} \\
W *_{31}=\frac{\Gamma \lambda_{p} \sigma_{e m}\left(\lambda_{p}\right)}{h c S_{e f f}}\left|A_{p}\right|^{2}=0
\end{gathered}
$$

The rate equation for the ground state population for the three-level model:

$$
\frac{d n_{1}}{d t}=-W *_{12} n_{1}-W *_{13} n_{1}+\left(W *_{21}+\frac{1}{\tau_{21}}\right) n_{2}=-\left(W *_{12}+W *_{13}\right) n_{1}+\left(W *_{21}+\frac{1}{\tau_{21}}\right) n_{2}
$$

Recalling expressions for $W_{12}, W_{21}$ (Equations (3) and (4)), we obtain:

$$
\begin{gathered}
W_{12}=\frac{\Gamma \lambda_{p} \sigma_{a b s}\left(\lambda_{p}\right)}{h c S_{e f f}}\left|A_{p}\right|^{2}+\frac{\Gamma}{h c S_{e f f}} \sum_{l} \lambda_{s, l} \sigma_{a b s}\left(\lambda_{s, l}\right)\left|A_{s, l}\right|^{2}=W *_{13}+W *_{12} \\
W_{21}=W *_{21}
\end{gathered}
$$

and the rate Equation (A5) for the ground state population for the three-level model becomes

$$
\frac{d n_{1}}{d t}=-W_{12} n_{1}+\left(W_{21}+\frac{1}{\tau_{21}}\right) n_{2}
$$

Therefore, Equation (A8) coincides with Equation (2). The expressions for $g_{\mathrm{p}}$ and $g_{\mathrm{s}, 1}$ for the three-level model coincide with expressions (7) and (8). Therefore, the two-level and quasi three-level models give the same results for in-band pumped Tm-doped tellurite glass microlasers.

\section{References}

1. Pasquazi, A.; Peccianti, M.; Razzari, L.; Moss, D.J.; Coen, S.; Erkintalo, M.; Chembo, Y.K.; Hansson, T.; Wabnitz, S.; Del'Haye, P.; et al. Micro-combs: A novel generation of optical sources. Phys. Rep. 2018, 729, 1-81. [CrossRef]

2. Yu, M.; Okawachi, Y.; Griffith, A.G.; Picqué, N.; Lipson, M.; Gaeta, A.L. Silicon-chip-based mid-infrared dual-comb spectroscopy. Nat. Commun. 2018, 9, 1869. [CrossRef]

3. Voloshin, A.S.; Kondratiev, N.M.; Lihachev, G.V.; Liu, J.; Lobanov, V.E.; Dmitriev, N.Y.; Weng, W.; Kippenberg, T.J; Bilenko, I.A. Dynamics of soliton self-injection locking in optical microresonators. Nat. Commun. 2021, 12, 235. [CrossRef] [PubMed]

4. Suh, M.G.; Yi, X.; Lai, Y.H.; Leifer, S.; Grudinin, I.S.; Vasisht, G.; Martin, E.C.; Fitzgerald, M.P.; Doppmann, G.; Wang, J.; et al. Searching for exoplanets using a microresonator astrocomb. Nat. Photonics 2019, 13, 25-30. [CrossRef] [PubMed] 
5. Pfeifle, J.; Brasch, V.; Lauermann, M.; Yu, Y.; Wegner, D.; Herr, T.; Hartinger, K.; Schindler, P.; Li, J.; Hillerkusset, D.; et al. Coherent terabit communications with microresonator Kerr frequency combs. Nat. Photonics 2014, 8, 375-380. [CrossRef] [PubMed]

6. Zhang, S.; Silver, J.M.; Shang, X.; Del Bino, L.; Ridler, N.M.; Del'Haye, P. Terahertz wave generation using a soliton microcomb. Opt. Express 2019, 27, 35257-35266. [CrossRef]

7. Anashkina, E.A.; Marisova, M.P.; Andrianov, A.V.; Akhmedzhanov, R.A.; Murnieks, R.; Tokman, M.D.; Skladova, L.; Oladyshkin, I.V.; Salgals, T.; Lyashuk, I.; et al. Microsphere-Based Optical Frequency Comb Generator for 200 GHz Spaced WDM Data Transmission System. Photonics 2020, 7, 72. [CrossRef]

8. Salgals, T.; Alnis, J.; Murnieks, R.; Brice, I.; Porins, J.; Andrianov, A.V.; Anashkina, E.A.; Spolitis, S.; Bobrovs, V. Demonstration of a fiber optical communication system employing a silica microsphere-based OFC source. Opt. Express 2021, 29, 10903-10913. [CrossRef] [PubMed]

9. Braunfelds, J.; Murnieks, R.; Salgals, T.; Brice, I.; Sharashidze, T.; Lyashuk, I.; Ostrovskis, A.; Spolitis, S.; Alnis, J.; Porins, J.; et al. Frequency comb generation in WGM microsphere based generators for telecommunication applications. Quantum Electron. 2020, 50, 1043-1049. [CrossRef]

10. Reynolds, T.; Riesen, N.; Meldrum, A.; Fan, X.; Hall, J.M.; Monro, T.M.; François, A. Fluorescent and lasing whispering gallery mode microresonators for sensing applications. Laser Photonics Rev. 2017, 11, 1600265. [CrossRef]

11. He, L.; Özdemir, Ş.K.; Yang, L. Whispering gallery microcavity lasers. Laser Photonics Rev. 2013, 7, 60-82. [CrossRef]

12. Soria, S.; Berneschi, S.; Brenci, M.; Cosi, F.; Nunzi Conti, G.; Pelli, S.; Righini, G.C. Optical Microspherical Resonators for Biomedical Sensing. Sensors 2011, 11, 785-805. [CrossRef] [PubMed]

13. Toropov, N.; Cabello, G.; Serrano, M.P.; Gutha, R.R.; Rafti, M.; Vollmer, F. Review of biosensing with whispering-gallery mode lasers. Light Sci. Appl. 2021, 10, 42. [CrossRef] [PubMed]

14. Reinis, P.K.; Milgrave, L.; Draguns, K.; Brice, I.; Alnis, J.; Atvars, A. High-Sensitivity Whispering Gallery Mode Humidity Sensor Based on Glycerol Microdroplet Volumetric Expansion. Sensors 2021, 21, 1746. [CrossRef]

15. Han, Z.; Fast, S.S.; Klotz, E.; Vatnik, I.D.; Churkin, D.V. Optical filtering with axial whispering gallery modes on the surface of tapered optical fibers. Laser Phys. Lett. 2020, 17, 066201. [CrossRef]

16. Righini, G.C.; Dumeige, Y.; Feron, P.; Ferrari, M.; Nunzi Conti, G.; Ristic, D.; Soria, S. Whispering gallery mode microresonators: Fundamentals and applications. La Riv. Del Nuovo Cim. 2011, 34, 435-488. [CrossRef]

17. Pal, A.; Chen, S.Y.; Sen, R.; Sun, T.; Grattan, K.T.V. A high-Q low threshold thulium-doped silica microsphere laser in the $2 \mu \mathrm{m}$ wavelength region designed for gas sensing applications. Las. Phys. Lett. 2013, 10, 085101. [CrossRef]

18. Anashkina, E.A. Laser Sources Based on Rare-Earth Ion Doped Tellurite Glass Fibers and Microspheres. Fibers 2020, 8, 30. [CrossRef]

19. Wu, J.; Jiang, S.; Qua, T.; Kuwata-Gonokami, M.; Peyghambarian, N. 2 um lasing from highly thulium doped tellurite glass microsphere. Appl. Phys. Lett. 2005, 87, 211118. [CrossRef]

20. Vanier, F.; Côté, F.; El Amraoui, M.; Messaddeq, Y.; Peter, Y.A.; Rochette, M. Low-threshold lasing at 1975 nm in thulium-doped tellurite glass microspheres. Opt. Lett. 2015, 40, 5227-5230. [CrossRef] [PubMed]

21. Wang, P.; Yi, Y.; Wang, X.; Li, A.; Jia, S.; Fan, Y.; Brambilla, G.; Wang, S.; Zhao, H. Tm ${ }^{3+}$-doped fluorotellurite glass microsphere resonator laser at $2.3 \mu \mathrm{m}$. Opt. Lett. 2020, 45, 3553-3556. [CrossRef]

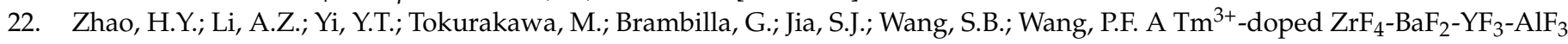
glass microsphere laser in the $2.0 \mu \mathrm{m}$ wavelength region. J. Lumin. 2019, 212, 207-211. [CrossRef]

23. Yang, K.; Dai, S.; Wu, Y.; Nie, Q. Fabrication and characterization of Ge-Ga-Sb-S glass microsphere lasers operating at $1.9 \mu \mathrm{m}$. Chin. Phys. B 2018, 27, 117701. [CrossRef]

24. Yu, J.; Wang, X.; Li, W.; Zhang, M.; Zhang, J.; Tian, K.; Du, Y.; Nic Chormaic, S.; Wang, P. An experimental and theoretical investigation of a $2 \mu \mathrm{m}$ wavelength low-threshold microsphere laser. J. Lightwave Technol. 2020, 38, 1880-1886. [CrossRef]

25. Yang, Z.; Wu, Y.; Yang, K.; Xu, P.; Zhang, W.; Dai, S.; Xu, T. Fabrication and characterization of Tm ${ }^{3+}-\mathrm{Ho}^{3+} \mathrm{co}^{-\mathrm{dop}} \mathrm{ed}$ tellurite glass microsphere lasers operating at $\sim 2.1 \mu \mathrm{m}$. Opt. Mater. 2017, 72, 524-528. [CrossRef]

26. Li, A.; Yu, J.; Zhang, M.; Lu, X.; Zhang, J.; Lewis, E.; Farrell, G.; Wang, P. An $\mathrm{Yb}^{3+}-\mathrm{Ho}^{3+}$ codoped glass microsphere laser in the 2.0 $\mu \mathrm{m}$ wavelength regions. IEEE Photonics Technol. Lett. 2018, 30, 1543-1546. [CrossRef]

27. Richards, B.D.; Jha, A. Lasers utilising tellurite glass-based gain media. In Technological Advances in Tellurite Glasses; Rivera, V.A.G., Manzani, D., Eds.; Springer Series in Materials Science; Springer: Cham, Switzerland, 2017; Volume 254, pp. 101-130. [CrossRef]

28. Saffari, M.; Gholami, A.; Parsanasab, G.M.; Firouzeh, Z.H. Investigation of a high-power low-threshold single-mode microsphere laser using a serially coupled double microsphere structure. J. Lightwave Technol. 2019, 37, 3273-3279. [CrossRef]

29. Anashkina, E.A.; Leuchs, G.; Andrianov, A.V. Numerical simulation of multi-color laser generation in Tm-doped tellurite microsphere at 1.9, 1.5 and 2.3 microns. Results Phys. 2020, 16, 102811. [CrossRef]

30. Min, B.; Kippenberg, T.J.; Yang, L.; Vahala, K.J.; Kalkman, J.; Polman, A. Erbium-implanted high-Q silica toroidal microcavity laser on a silicon chip. Phys. Rev. A 2004, 70, 033803. [CrossRef]

31. Mescia, L.; Bia, P.; De Sario, M.; Di Tommaso, A.; Prudenzano, F. Design of mid-infrared amplifiers based on fiber taper coupling to erbium-doped microspherical resonator. Opt. Express 2012, 20, 7616-7629. [CrossRef]

32. Gomes, L.; Lousteau, J.; Milanese, D.; Scarpignato, G.C.; Jackson, S.D. Energy transfer and energy level decay processes in $\mathrm{Tm}^{3+}$-doped tellurite glass. J. Appl. Phys. 2012, 111, 063105. [CrossRef] 
33. Denker, B.I.; Dorofeev, V.V.; Galagan, B.I.; Motorin, S.E.; Sverchkov, S.E. $2.3 \mu \mathrm{m}$ laser potential of TeO 2 based glasses. Laser Phys. 2021, 27, 095801. [CrossRef]

34. Muravyev, S.V.; Anashkina, E.A.; Andrianov, A.V.; Dorofeev, V.V.; Motorin, S.E.; Koptev, M.Y.; Kim, A.V. Dual-band Tm ${ }^{3+}$-doped tellurite fiber amplifier and laser at $1.9 \mu \mathrm{m}$ and $2.3 \mu \mathrm{m}$. Sci. Rep. 2018, 8, 16164. [CrossRef] [PubMed]

35. Svelto, O. Principles of Lasers; Springer Science + Business Media LLC: New York, NY, USA, 2010.

36. Andrianov, A.V.; Marisova, M.P.; Dorofeev, V.V.; Anashkina, E.A. Thermal shift of whispering gallery modes in tellurite glass microspheres. Res. Phys. 2020, 17, 103128. [CrossRef]

37. Andrianov, A.V.; Anashkina, E.A. Tunable Raman lasing in an $\mathrm{As}_{2} \mathrm{~S}_{3}$ chalcogenide glass microsphere. Opt. Express 2021, 29, 5580-5587. [CrossRef]

38. Andrianov, A.V.; Anashkina, E.A. Single-mode silica microsphere Raman laser tunable in the U-band and beyond. Res. Phys. 2020, 17, 103084. [CrossRef]

39. Sasagawa, K.; Yonezawa, Z.O.; Iwai, R.; Ohta, J.; Nunoshita, M. S-band $\mathrm{Tm}^{3+}{ }^{3+}$ doped tellurite glass microsphere laser via a cascade process. Appl. Phys. Lett. 2004, 85, 4325-4327. [CrossRef]

40. $\mathrm{Wu}$, J.; Jiang, S.; Peyghambarian, N. 1.5- $\mu \mathrm{m}$-band thulium-doped microsphere laser originating from self-terminating transition. Opt. Express 2005, 13, 10129-10133. [CrossRef] 